\title{
Cytochrome Systems
}

\section{Molecular Biology and Bioenergetics}

\author{
Edited by \\ S. Papa \\ University of Bari \\ Bari, Italy \\ B. Chance \\ University of Pennsylvania \\ Philadelphia, Pennsylvania \\ and \\ L. Ernster \\ University of Stockholm \\ Stockholm, Sweden
}

Plenum Press • New York and London 


\section{Library of Congress Cataloging in Publication Data}

UNESCO International Workshop on Cytochrome Systems: Molecular Biology and Bioenergetics (1987: Bari, Italy)

Cytochrome systems.

"Proceedings of the UNESCO International Workshop on Cytochrome Systems: Molecular Biology and Bioenergetics, which was IUB Symposium No. 159, held April 14-18, 1987, in Bari, Italy"-Verso t.p.

Includes bibliographical references and index.

1. Cytochrome-Congresses. I. Papa, S. II. Chance, Britton. III. Ernster, L. IV. Title.

The Symposium was generously supported by the following organizations:

UNESCO European Expert Committee on Biomaterials

International Union of Biochemistry, Committee on Symposia

International Union of Pure and Applied Biophysics

Consiglio Nazionale delle Ricerche

Università di Bari

Regione Puglia

Calabrese Veicoli Industriali S.p.A., Bari

Sigma Chemical Company

Proceedings of the UNESCO International Workshop on Cytochrome Systems: Molecular Biology and Bioenergetics, which was IUB Symposium No. 159, held April 14-18, 1987, in Bari, Italy

(C) 1987 Plenum Press, New York

A Division of Plenum Publishing Corporation

233 Spring Street, New York, N.Y. 10013

All rights reserved

No part of this book may be reproduced, stored in a retrieval system, or transmitted in any form or by any means, electronic, mechanical, photocopying, microfilming, recording, or otherwise, without written permission from the Publisher

Printed in the United States of America 


\section{CONTENTS}

\section{INTRODUCTION}

Cytochrome Systems: from Discovery to Present Developments

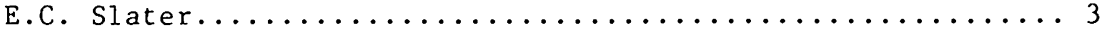

\section{GENETICS}

Genetics of E.Coli Cytochromes which are Components of the Aerobic Respiratory Chain

R.B. Gennis..........................

Molecular Genetic Approaches to Studying the Structure and

Function of the Cytochrome $\mathrm{c}_{2}$ and the Cytochrome bc, Complex from Rhodobacter Capsulatus

F. Daldal........................... 23

Structural Homologies in the Cytochrome $B / C_{1}$ Complex from Rhodobacter

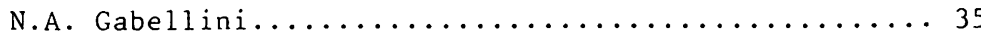

Genes and Sequences for Subunits of Respiratory Complexes in Paracoccus denitrificans

B. Ludwig, B. Kurowski, G. Panskus and P. Steinrücke.. 41

Organization and Expression of Nuclear Genes for Yeast

Cytochrome c Oxidase

R.M. Wright, J.D. Trawick, C.E. Trueblood,

T.E. Patterson and R.0. Poyton.............. 4

The cDNA a Structural Gene for Rat Liver Cytochrome c

Oxidase Subunit VIc

G. Suske, C. Enders, T. Mengel and B. Kadenbach..... 57

Genetics of Yeast Coenzyme $\mathrm{QH}_{2}$-Cytochrome c Reductase

M. Crivellone, A. Gampel, I. Muroff, M. Wu and

A. Tzagoloff......................... 67

Sequence Analysis of Mammalian Cytochrorne b Mutants

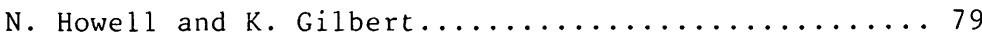

Plant Mitochondrial Genes, Cytochrome $c$ Oxidase and Cytoplasmic Male Sterility

M.J. Hawkesford and C.J. Leaver............. 87 
A Mutation Affecting Lariat Formation, but not Splicing of a Yeast Mitochondrial Group II Intron

R. van der Veen, J.H.J.M. Kwakman and L.A. Grivel1...

The Evolution of Mitochondrially Coded Cytochrome Genes:

A Quantitative Estimate

C. Saccone, M. Attimonelli, C. Lanave, R. Gallerani

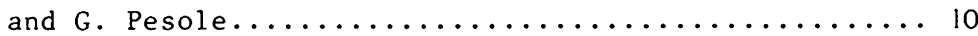

Involvement of Nuclear Genes in Splicing of the Mitochondrial

COB Transcript in S. Cerevisiae

J. Kreike, G. Krummeck, T. Söllner, C. Schmidt and

R.J. Schweyen..............................

Introns as Key Elements in the Evolution of Mitochondrial

Genomes in Lower Eukaryotes

K. Wolf, A. Ahne, L. Del Giudice, G. Oraler,

F. Kanbay, A.M. Merlos-Lange, F. Welser and

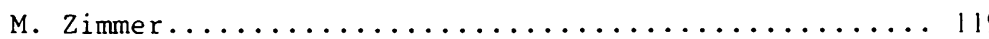

I. GENETICS: Short Reports

Core Protein Deficiency in Complex III of the Respiratory Chain, in a Missence Exonic Mitochondrial Yeast Mutant of Cytochrome b Gene

P. Chevillotte-Brivet, G. Salou and

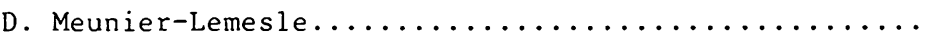

Localization and Partial Sequencing Analysis of Mitochondrial Gene for Apocytochrome b in Sunflower

D. Pacoda, A.S. Treglia, L. Siculella, C. Perrotta

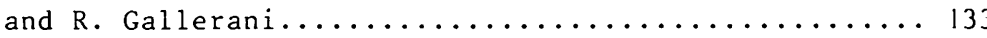

Molecular Basis for Resistance to Inhibitors of the Mitochondrial Ubiquinol-Cytochrome c Reductase in Saccharmoyces Cerevisiae

A.M. Colson, B. Meunier and J.P. di Rago...........

Structure of the Proteins and Genes for the Nuclear-Encoded Subunits of $\mathrm{N}$. Crassa Cytochrome Oxidase

M.D. Suarez, M. Sachs, M. David and U.L. RajBhandary.. 137

Partial Sequence of Gene for Cytochrome Oxydase Subunit II of Sunflower Mitochondrial DNA

L.R. Ceci, C. De Benedetto, C.M. Perrotta, L. Siculella

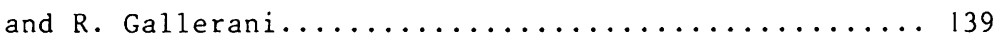

Unusual Features of Kinetoplast DNA from Trypanosomes: Novel Mechanism of Gene Expression (RNA-Editing), the Absence of tRNA Genes and the Variable Presence of a Cytochrome Oxidase Subunit Gene

P. Sloof, R. Benne; B. De Vries, T. Hakvoort and A. Muijsers............................ 14 
Heterogeneous Efficiencies of mRNA Translation in

Human Mitochondria

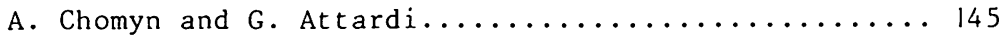

Regulation of the Expression of COI and COIII mRNAs in Rat Liver Mitochondria

P. Cantatore, F. Fracasso, A.M.S. Lezza and

M.N. Gadaleta........................ 153

Two Consensus Sequences for RNA Processing in Neurospora

Crassa Mitochondria

G. Macino and M.A. Nelson..................... 161

Primary Structure of the Yeast Nuclear CBSI Gene Product, Necessary to Activate Translation of Mitochondrial COB mRNA

V. Forsbach and G. Rödel

A Calmodulin-Like Protein in the Cytochrome bc, Complex Required for Synthesis of Both Cytochrome bc, and Cytochrome c Oxidase Complexes in Yeast Mitochondria

M.E. Schmitt and B.L. Trumpower..................

Import of Cytochromes $b_{2}$ and $c_{1}$ into Mitochondria is Dependent on Both Membrane Potential and Nucleoside Triphosphates

F.U. Hartl, J. Ostermann, N. Pfanner, M. Tropschug,

B. Guiard and W. Neupert................... 189

NADH: A Common Requirement for the Import and Maturation of Cytochromes $c$ and $c$,

D.W. Nicholson, J. Ostermann and W. Neupert..........

Import of Proteins into Mitochondria: Structural and

Functional Role of the Prepeptide

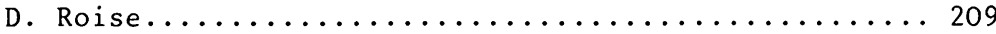

Interaction of the Mitochondrial Precursor Protein Apocytochrome $c$ with Model Membranes and its Implications for Protein Translocation

B. de Kruijff, A. Rietveld, W. Jordi, T.A. Berkhout,

R.A. Demel, H. Görrissen and D. Marsh........... 215

Influence of Thyroid Hormones on the Expression of Nuclear Genes Encoding Subunits of the Cytochrome bc, Complex

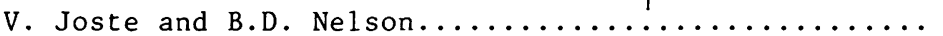

II. BIOSYNTHESIS: Short Report

Import of Cytochrome $c_{1}$ and Cytochrome $b_{2}$ into Mitochondria

J. Ostermann, F.U. Hartl, M. Tropschung, B. Guiard

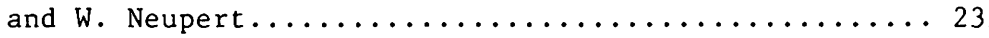


III. PROTEIN STRUCTURE

Cytochrome c Oxidase: Past, Present and Future

M. Müller, N. Labonia, B. Schläpfer and A. Azzi..... 237

Universal Features in Cytochrome Oxidase

M. Finel, T. Haltia, L. Holm, T. Jalli, T. Metso,

A. Puustinen, M. Raitio, M. Saraste and

M. Wikström........................ 24

Polypeptide Subunits Encoded by Nuclear Genes are Essential

Components of Eukaryotic Cytochrome $c$ Oxidase

T.E. Patterson, C.E. Trueblood, R.M. Wright and

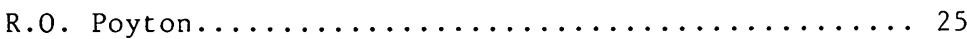

Respiratory Complex IV and Cytochrome $a, a_{3}$

G. Buse, G.C.M. Steffens, R. Biewald, B. Bruch and

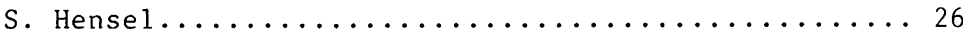

An Amino Acid Sequence Region of Subunit II of Cytochrome Oxidase which may be Responsible for Evolutionary Changes in Reactivity with Different Cytochromes $c$

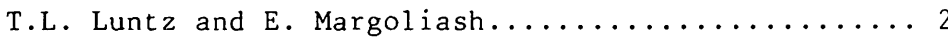

Evidence for a Functional Role of Nuclear Encoded Subunits in Mitochondrial Cytochrome $C$ Oxidase

R. Bisson and B. Bacci................... 28

Structural Analysis of the bc, Complex from Beef Heart Mitochondria by the Sided Hydropathy Plot and by Comparison with Other bc, Complexes

T.A. Link, H. Schägger and G. von Jagow......... 289

Crystallisation of Water-Soluble Preparations of the IronSulfur-Protein and Cytochrome $c_{\text {, }}$ of Ubiquinol: Cytochrome Reductase from Neurospora Mitochondria

J. Römisch, U. Harnisch, U. Schulte and H. Weiss.... 303

Iron Cluster Sites of Cardiac Ip-Subunit of Succinate Dehydrogenase

T.E. King, N.S. Reimer, M.T. Seaman, L.Q. Sun,

Q.W. Wang, K.T. Yasunobu and S.H. Ho.............. 309

Polypeptides in Mitochondrial Electron-Transfer Complexes

T. Ozawa, M. Nishikimi, H. Suzuki, M. Tanaka and

Y. Shimomura........................... 315

The Fatty Acid-Anchored Four Heme Cytochrome of the Photosynthetic Reaction Center from the Purple Bacterium Rhodopseudomonas Viridis

K.A. Weyer, F. Lottspeich, W. Schäfer and

H. Michel............................ 325 
III. PROTEIN STRUCTURE: Short Reports

Membrane Protein in Paracoccus Denitrificans Resembles

Subunit III of Beef Heart Cytochrome Oxidase

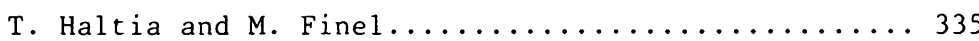

The Circular Dichroism Properties of the Rieske Protein

and the $b$ and $c$, Cytochromes of the Mitochondrial

bc, Complex

G. Solaini, M. Crimi, F. Ballester, M. Degli Esposti

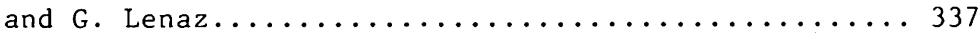

Monomerization of Cytochrome Oxidase Might Be Essential

for Subunit III Removal

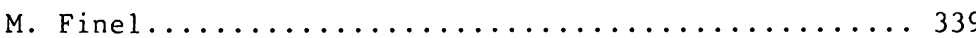

Fourier-Transform Infra-Red Studies of Cytochrome c Oxidase

M.F. Grahn, P.I. Haris, J.M. Wrigglesworth and

D. Chapman............................... 341

Isoenzymes of Human Cytochrome $c$ Oxidase

T.B.M. Hakvoort, G.J.C. Ruyter, K.M.C. Sinjorgo and

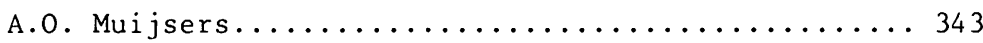

Folding of Integral Membrane Proteins: Renaturation Experiments with Bacteriorhodospin Support a Two-Stage Mechanism

J.L. Popot and D.M. Engelman................ 345

IV. REACTION DOMAINS AND OXIDO-REDUCTION MECHANISMS

The Nature of Ferryl, $\mathrm{Fe}(\mathrm{IV})=0$, Haem in Peroxidases

A.J. Thomson, C. Greenwood, P.M.A. Gadsby and

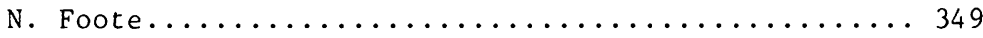

Polarization in Heme Proteins and Cytochrome c Oxidase

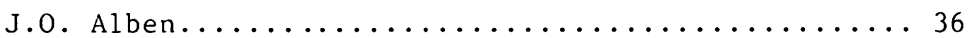

Effects of Freezing on the Coordination State and Ligand

Orientation in Hemoproteins

H. Anni and T. Yonetani................... 37

Catalytic Mechanism of $\mathrm{O}_{2}$ Reduction by Cytochrome Oxidase

M. Wikström......................... 377

The Electron-Transfer Reactions in and Substrate Binding to Cytochrome $\underline{c}$ Oxidase

B.F. van Gelder, A.C.F. Gorren, L. Vlegels and

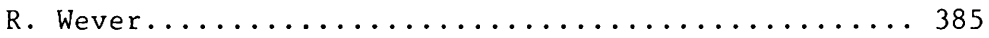

Control of Cytochrome Oxidase in Proteoliposomes: Flux and Stoichiometry

P. Nicholls, S. Shaughnessy and A.P. Singh.

Cytochrome c Oxidase Activity is Regulated by Nucleotides

and Anions

B. Kadenbach, A. Stroh, F.J. Hüther and J. Berden.... 399 
Cytochrome Oxidase and Neuromuscular Diseases

C.P. Lee, M.E. Martens, P.L. Peterson and

J.S. Hatfield....................... 407

Electron Transfer Between Cardiac Cytochrome $c$, and $c$ C.H. Kim, C. Balny and T.E. King............. 415

Heme Cluster Structures and Electron Transfer

in Multiheme Cytochromes $\mathrm{C}_{3}$

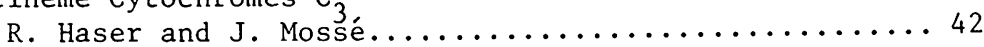

IV. REACTION DOMAINS AND OXIDO-REDUCTION MECHANISMS: Short Reports

Electron Exchange Between Cytochromes $\underline{a}$

P. Sarti, F. Malatesta, G. Antonini, M.T. Wilson and

M. Brunori........................ 433

Pulsed, Resting and Peroxy Forms of Cytochrome Oxidase

G. Antonini, F. Malatesta, P. Sarti, M.T. Wilson and

M. Brunori.......................... 435

Effect of $\mathrm{pH}$ and Temperature on Electron Transfer in MixedValence Cytochrome c Oxidase

P. Brezezinski and Bo.G. Malmström

The pH-Dependence of the Reductional Levels of Cytochrome

$c$ and Cytochrome a During Turnover of Cytochrome c Oxidase

P.E. Thörnstrom, B. Maison-Peteri, P. Brzezinski,

L. Arvidsson, P.O. Fredriksson and Bo.G. Malmström....

V. Fe-S CENTERS

Studies of Bacterial NADH-Ubiquinone (or Menaquinone)

Oxidoreductase Systems

T. Ohnishi, S.W. Meinhardt and K. Matsushita....... 443

Localized Valence States in Iron-Sulfur Clusters and Their Possible Relationship to the Ability of Iron-Sulfur Clusters to Catalyze Reactions Other Than Electron Transfer

H. Beinert......................... 451

Probing the Fe/S Domain With EPR: Pandora's BOX Ajar

W.R. Hagen......................... 4

Aspects of Spin Coupling Between Even and Odd Electron

Systems: Applications to Succinate: Q Reductase

J.C. Salerno and Xu Yan.................. 467

The Iron-Sulfur Clusters in Succinate Dehydrogenase

M.K. Johnson, J.E. Morningstar, E.B. Kearney,

G. Cecchini and B.A.C. Ackrell............... 473

Mechanisms of Electron Transfer in Succinate Dehydrogenase

and Fumarate Reductase: Possible Functions for Iron-Sulphur

Centre 2 and Cytochrome $\underline{b}$

R. Cammack, J. Maguire and B.A.C. Ackrell........ 485 
VI. QUINONE BINDING SITES:STRUCTURE AND FUNCTION

Structural and Mechanistic Aspects of the Quinone Binding Sites of the bc Complexes

P.R. Rich............................ 495

QP-S-The Electron Acceptor of Succinate Dehydrogenase

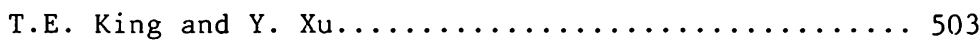

Characteristics of $\mathrm{QP}-\mathrm{C}$ and Reconstitution of the

$\mathrm{QH}_{2}-$ Cyt $c$ reductase

T.Y. Wang, Z.P. Zhang and T.E. King.......... 509

The Kinetics of Oxidation of Cytochrome b are in Agreement

with the Q-Cycle Hypothesis

S. De Vries, A.N. van Hoek, A. ten Bookum and

J.A. Berden.......................... 51

The Q-Reaction Domains of Mitochondrial $\mathrm{QH}_{2}$ : Cytochrome $\underline{\mathrm{c}}$ Oxidoreductase

J.A. Berden, A.N. Jan Hoek, S. de Vries and

P.J. Schoppink........................ 523

EPR Studies of the Quinone Reaction Sites in Bacteria

S.W. Meinhardt, X. Yang, B.L. Trumpower and

T. Ohnishi.......................... 53

EPR Signal II in Photosystem II: Redox and Paramagnetic

Interactions with the $\mathrm{O}_{2}$ Evolving Enzyme

A.W. Rutherford and S. Styring............. 541

Studies on the Ubiquinone Pool in Mitochondrial Electron

Transfer

G. Lenaz, R. Fato and G. Parenti Castelli.........549

VI. QUINONE BINDING SITES: STRUCTURE AND FUNCTION: Short Reports

Effects of Proteolytic Digestion and Chemical Modification

of $b-c_{1}$ Complex on the Fe-S Center and the Stable Ubisemiquinone ( $S Q c)$

T. Cocco, S. Meinhardt, D. Gatti, M. Lorusso,

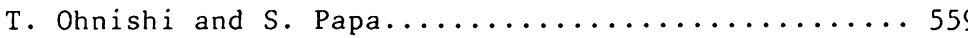

Kinetics of Ubiquinol Cytochrome c Reductase: Lack of a

Diffusion-Limited Step with Short Chain Ubiquinols as

Substrates

R. Fato, C. Castelluccio, G. Lenaz, M. Battino

and G. Parenti Castelli................... 561

VII. SPECIFIC REDOX SYSTEMS

Biochemistry and Molecular Biology of the Escherichia Coli

Aerobic Respiratory Chain

Y. Anraku........................... 565 
The Interplay Between Photosynthesis and Respiration in Facultative Anoxygenic Phototrophic Bacteria

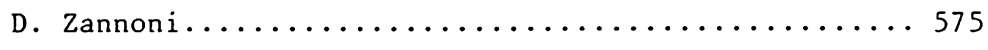

The Ubiquinol-Cytochrome c Oxidoreductase of Phototrophic Bacteria

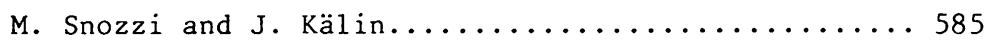

The Redox Reaction Between Cytochrome $b_{H}$ and the Semiquinone-Quinol Couple of $Q_{C}$ is Electrogenic in UbiquinolCyt $c_{2}$ Oxidoreductase

D.E. Robertson and P.L. Dutton.............. 593

Construction and Characterization of Monolayer Films of the Reaction Center Cytochrome- $\underline{c}$ Protein from Rhodopseudomonas Viridis

G. Alegria and P.L. Dutton...................6 601

Structure-Function Relationships in the Rhodopseudomonas

Viridis Reaction Center Complex: Electrogenic Steps Contributing to $\Delta \psi$ Formation

V.P. Skulachev, L.A. Drachev, S.M. Dracheva,

A.A. Konstantinov, A.Yu. Semenov and V.A. Shuvalov...609

Catalytic Sites for Reduction and Oxidation of Quinones

A. Crofts, H. Robinson, K. Andrews, S. van Doren

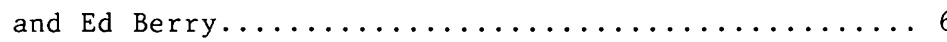

Studies of the Electrogenicity of the Reduction of Cytochrome $b_{56}$ through the Antimycin-Sensitive Site of the Ubiquino1-Cytochrome $c_{2}$ Oxidoreductase Complex of Rhodobacter Sphaeroides

E. Glaser and A.R. Crofts...................6 625

Mutants Affecting the Quinol Oxidation Site of UbiquinolCyt $c_{2}$-Oxidoreductase

D.E. Robertson, F. Daldal and P.L. Dutton......... 633

Cytochrome $b_{558}$ of Bacillus Subtilis

H. Fridén and L. Hederstedt................... 641

Mitochondrial Cytochrome $\mathrm{b}_{560}$

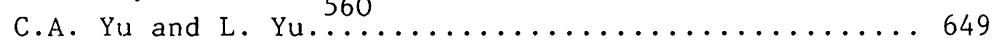

Isolation of the Photosystem Two Reaction Centre and the

location and Function of Cytochrome $b_{559}$

J. Barber, K. Gounaris and D.J. ${ }^{559}$ Chapman......... 657

VII. SPECIFIC REDOX SYSTEMS: Short Reports

Effect of Antimycin on the Kinetics of Reduction of $b$ and $c$, Cytochromes in Single Turnover of the Mitochondrial $\mathrm{b}-\mathrm{c}_{1}$ Complex

D. Boffoli, M. Lorusso and S. Papa..............669

The $b-Q$ Cycle, a new model for the Pathways of Electrons and Protons through the bc, Complex: Action of Antimycin A at Center 0

D. Meunier-Lemesle and P. Chevillotte-Brivet........ 
Rapid Oxidation Kinetics of Quinol Cytochrome c

Oxidoreductase: Quinone or Semiquinone Cycle?

A.N. van Hoek, J.A. Berden and S. De Vries.........6 675

Electron Conduction Between b Cytochromes of the Mitochondrial Respiratory Chain in the Presence of Antimycin plus Myxothiazol

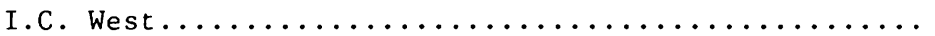

The Release of NAD Radical is the Limiting Step in the Redox Reaction Between Fe(III) Cytochrome $c$ and NADH

A. Ferri, P. Chiozzi, M.E. Cattozzo and D. Patti..... 681

Properties of Cytochrome $b_{558}$ in Complex II of Ascaris

Muscle Mitochondria and its Function in Anaerobic Respiration

K. Kita, S. Takamiya, R. Furushima, Y. Ma and

H. Oya.

\section{COOPERATIVITY AND ALLOSTERIC TRANSITIONS}

Pulsed and Resting Cytochrome Oxidase: an Update of Optical and Molecular Properties

M. Brunori, P. Sarti, F. Malatesta, G. Antonini and

M.T. Wilson........................ 689

Is $\mathrm{H}_{2} \mathrm{O}$ Involved in Electron Transport Between Cytochromes a and $\underline{a}_{3}$ in Cytochrome Oxidase?

J.M. Wrigglesworth, M.F. Grahn, J. Elsden and

H. Baum.............................697

Conformational Transitions of Cytochrome $c$ Oxidase Induced by Partial Reduction

C.P. Scholes, C. Fan, J. Bank, R. Dorr and

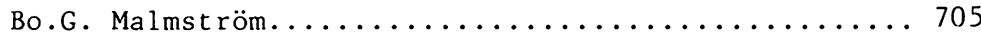

Redox-Linked Conformational Changes in Cytochrome $c$ Oxidase

T. Alleyne and M.T. Wilson................. 713

\section{PROTON-MOTIVE ACTIVITY}

Protonmotive Activity of the Cytochrome Chain of Mitochondria: Models and Features

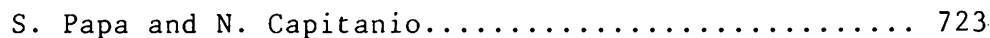

The Mechanism of Electron Gating in Cytochrome c Oxidase

Bo.G. Malmström..................... 733

Proton Pump Activity in Bacterial Cytochrome Oxidases

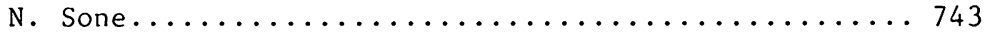

Topography and Protonmotive Mechanism of Mitochondrial

Coupling Site 2

A.A. Konstantinov and E. Popova................ 751 
The Q-Gated Proton Pump Model of Ubiquinol Cytochrome c Reductase: Electron and Proton Transfer Pathways and Role of Polypeptides

M. Lorusso, D. Boffoli, T. Cocco, D. Gatti and

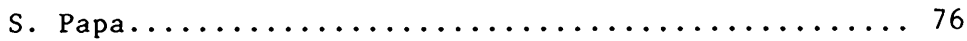

Photosynthetic Control and ATP/Electron Ratio in Bacterial

Photophosphorylation

V. Adam, M. Virgili, G. Venturoli, D. Pietrobon

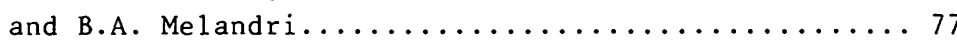

IX. PROTON-MOTIVE ACTIVITY: Short Report

Protonmotive Activity of Mitochondrial Cytochrome c Oxidase

N. Capitanio, E. De Nitto and S. Papa.

APPENDIX

Proposal for a Novel Nomenclature for the Subunits of Cytochrome c Oxidase

G. Buse, G.C.M. Steffens, R. Biewald, B. Bruch and

S. Hensel............................ 791

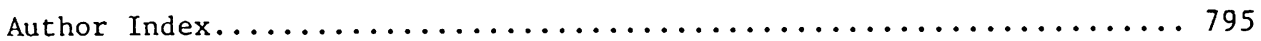

Subject Index.................................. 799 


\title{
IMPORT OF CYTOCHROMES $b_{2}$ AND $c_{1}$ INTO MITOCHONDRIA IS DEPENDENT
}

\section{ON BOTH MEMBRANE POTENTIAL AND NUCLEOSIDE TRIPHOSPHATES}

\author{
Franz-Ulrich Hartl, Joachim Ostermann, Nikolaus Pfanner, \\ Maximilian Tropschug, Bernard Guiard* and Walter Neupert \\ Institut für Physiologische Chemie, Goethestr. 33 \\ 8000 München 2, FRG, and \\ * Centre de Genetique Moleculaire, 91190 Gif-sur-Yvette \\ France
}

\section{SUMMARY}

Import of precursors of cytochromes $b_{2}$ and $c_{1}$ into mitochondria requires a mitochondrial membrane potential. We show here that in addition to $\Delta \psi$, nucleoside triphosphates (NTPs) are necessary for protein translocation. At low concentrations of NTPs, intermediate-sized cytochrome $\mathrm{b}_{2}$ was accumulated spanning the outer and inner membranes at contact sites. For complete translocation into mitochondria, higher concentrations of NTPs were necessary. We conclude that different levels of NTPs are required for distinct steps in the import pathway.

\section{INTRODUCTION}

Most mitochondrial proteins are coded for by the nucleus and are synthesized as precursors on cytoplasmic polysomes. Transport of proteins into mitochondria can be subdivided into several steps (for reviews see: Harmey and Neupert, 1985; Pfanner and Neupert, 1987; Hartl et al., 1987): (i) specific interaction with receptors on the mitochondrial surface; (ii) transport into mitochondria at translocation contact sites between outer and inner membranes; (iii) processing of precursors having N-terminal extensions by the processing peptidase in the matrix; (iv) additional modifications, including covalent or non-covalent attachment of cofactors or, in certain cases, a second proteolytic processing step; and (v) assembly into active supramolecular protein complexes.

Transport into or translocation across the inner membrane is dependent on an energized inner membrane (Hallermayer and Neupert, 1976; Nelson and Schatz, 1979; Zimmermann et al., 1981; Schleyer et al., 1982; Gasser et al., 1982; Kolanski et al., 1982). Energy is required in the form of the electrical component $\Delta \Psi$ of total protonmotive force (Pfanner and Neupert, 1985). For long, however, it could not be decided whether high energy phosphate compounds, such as ATP, are necessary in addition to $\Delta \boldsymbol{\Psi}$. Indeed, this was recently shown for the import of the $B$ subunit of F F 1 -ATPase $\left(F_{1} B\right.$ ) (Pfanner and Neupert, 1986), the ADP/ATPtranslocator of the inner membrane, and fusion proteins between F F -ATPase subunit 9 and dihydrofolate reductase (Pfanner et al., 1987 ).

In the present report we investigated whether the import of 
cytochromes $b_{2}$ and $c_{1}$ was dependent on NTPs. Cytochrome $b_{2}$ is a soluble component of the intermembrane space (Daum et al., 1982a). Cytochrome $c_{1}$ is anchored to the inner membrane but contains a large hydrophilic domain which protrudes into the intermembrane space ( $\mathrm{Li}$ et al., 1981). Compared to $B$ subunit of $F F_{1}$-ATPase their import and sorting pathways are more complex in that both precursor proteins are proteolytically processed in two steps (Daum et al., 1982b; Ohashi et al., 1982; Teintze et al., 1982). The first processing step is performed by the matrix peptidase, i.e. precursors have to be translocated either completely or at least partially across the inner membrane. The second processing event occurs at the outer surface of the inner membrane by a so far uncharacterized protease(s) (Pratje and Guiard, 1986). On addition both proteins have to acquire heme, which is covalently attached in case of cytochrome $c_{1}$.

Selective and independent manipulation of NTP levels and the membrane potential showed that import of cytochromes $b_{2}$ and $c_{1}$ required both NTPs and $\Delta \boldsymbol{\psi}$. Interestingly, at low levels of NTPs precursors were only partially translocated into mitochondria: they accumulated in translocation contact sites (Schleyer and Neupert, 1985).

\section{MATERIALS AND METHODS}

Growth of Neurospora crassa (wild type 74A) (Schleyer et al., 1982) and isolation of mitochondria by Percoll (Pharmacia) density gradient centrifugation was done as described (Hartl et al., 1986). Yeast cells of wild type Saccharomyces cerevisiae (D273-10B) were grown on $2 \%$ lactate and mitochondria were isolated according to Daum et al. (1982a). Mitochondria were finally suspended in SEM buffer $(250 \mathrm{mM}$ sucrose, $1 \mathrm{mM}$ EDTA, $10 \mathrm{mM}$ MOPS/KOH, $\mathrm{pH} 7.2$ ) at a protein concentration of $2.5 \mathrm{mg} / \mathrm{ml}$.

Precursor proteins were synthesized by coupled transcription/ translation. For cytochrome $c_{1}$, a full length cDNA was isolated from a $\mathrm{N}$. crassa library and cloned into $\mathrm{pGEM}_{4}$. For cytochrome $\mathrm{b}_{2}$, the genomic clone described previously (Guiard, 1985) was used.

Transcription/translation of the cloned sequences followed the methods of Krieg and Melton (1984) and Stueber et al. (1984), respectively.

Postribosomal supernatants were prepared and supplemented as published (Schleyer et al., 1982).

Labelled reticulocyte lysates and isolated mitochondria were treated with apyrase (Sigma, grade VIII) essentially as described before (Pfanner and Neupert, 1986). Afterwards reticulocyte lysates were cooled to $0^{\circ} \mathrm{C}$ and diluted with BSA buffer $(250 \mathrm{mM}$ sucrose, $80 \mathrm{mM} \mathrm{KCl}, 5 \mathrm{mM} \mathrm{MgCl}, 10 \mathrm{mM}$ MOPS, 3\% (w/v) BSA, pH 7.2). Antimycin A, oligomycin or valinomycin ( $8 \mu \mathrm{M}$, $20 \mu \mathrm{M}$ and $1 \mu \mathrm{M}$, respectively) were added from 100-fold concentrated stock solutions in ethanol when indicated. Mixtures for import into $\mathrm{N}$. crassa mitochondria contained $8 \mathrm{mM}$ potassium ascorbate and $0.2 \mathrm{mM} \mathrm{N}, \mathrm{N}^{\prime} \mathrm{N}^{\prime}, \mathrm{N}^{\prime}-$ tetramethylphenylenediamine (TMPD) as an energy source, whereas mixtures for yeast mitochondria included $20 \mathrm{mM}$ potassium succinate. Then mitochondria ( $50 \mu \mathrm{g}$ of protein) were added. In order to supplement NTPs, either ATP or GTP ( $8 \mathrm{mM}$ final concentration) were added from $200 \mathrm{mM}$ stock solutions in water. For neutralization sufficient amounts of $1 \mathrm{MMOPS} / \mathrm{NaOH}$, $\mathrm{pH} 7.2$, were included. Incubation was for $30 \mathrm{~min}$ at $25^{\circ} \mathrm{C}$ in a total volume of $100 \mathrm{\mu l}$. Mitochondria were then reisolated by centrifugation (15 min $27,000 \times \mathrm{g}$ ), resuspended in SEM buffer and treated with proteinase $\mathrm{K}$ (15 $\mu \mathrm{g} / \mathrm{ml}$ final concentration) as described (Hartl et al., 1986). Reisolated mitochondria were lysed in SDS sample buffer. SDS polyacrylamide electrophoresis and fluorography were carried out according to published methods (Laemmli, 1970; Hartl et al., 1986). 


\section{RESULTS}

Import of cytochromes $b_{2}$ and $c_{1}$ requires nucleoside
triphosphates

Reticulocyte lysates containing the ${ }^{35}$ S-methionine labelled precursor of cytochrome $b_{2}$ and freshly isolated yeast mitochondria were pretreated with different concentrations of apyrase, an adenosine 5'triphosphatase and adenosine 5'-diphosphatase which caused rapid depletion of endogenous ATP and ADP. Mitochondria and reticulocyte lysate were mixed in the presence of succinate (as a respiratory substrate) and oligomycin (which inhibits the F F -ATPase, Wikstrom and Krab, 1982). The latter was included to prevent reduction of the mitochondrial membrane potential by ATPase activity. Following incubation for 30 min at $25^{\circ} \mathrm{C}$, the samples were treated with proteinase $\mathrm{K}$ to digest cytochrome $b_{2}$ that had not been imported into mitochondria. Then mitochondria were reisolated and dissolved in SDS-containing buffer for subsequent

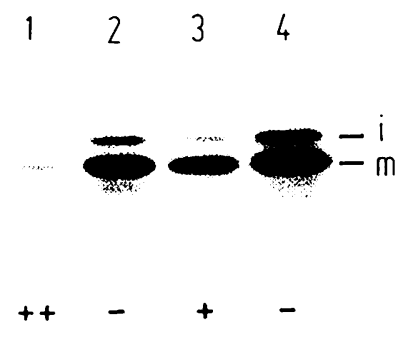

Fig. 1. Import of cytochrome $b_{2}$ into yeast mitochondria is inhibited by apyrase treatment.

Reticulocyte lysates containing labelled precursor of cytochrome $\mathrm{b}_{2}$ were incubated for $15 \mathrm{~min}$ at $30^{\circ} \mathrm{C}$ and $15 \mathrm{~min}$ at $25^{\circ} \mathrm{C}$ with apyrase: reactions 1 and 3 received 1 and $0.25 \mathrm{U} / \mathrm{ml}$, respectively; reactions 2 and 4 received corresponding amounts of inactivated apyrase. Mitochondria were added to the lysate in presence of succinate and oligomycin. Incubation for import was for $30 \mathrm{~min}$ at $25^{\circ} \mathrm{C}$. Afterwards the samples were cooled to $0^{\circ} \mathrm{C}$ and diluted 1:2 with SEM. Proteinase $K$ treatment was then performed $\left(30 \mathrm{~min}\right.$ at $\left.0^{\circ} \mathrm{C}\right)$. Protease activity was stopped by adding PMSF to $1 \mathrm{mM}$. Then mitochondria were reisolated by centrifugation and dissociated in SDS-containing buffer. The samples were analyzed by electrophoresis and fluorography. Abbreviations: $i$, intermediate; $m$, mature cytochrome $b_{2}$.

electrophoresis and fluorography. A fluorograph of the dried gel is shown in Fig.1. Control samples received an apyrase preparation which had been inactivated by heating to $95^{\circ} \mathrm{C}$ for $10 \mathrm{~min}$. In these reactions, cytochrome $b_{2}$ precursor was imported into a protease protected location and processed to the mature form. Besides mature cytochrome $b_{2}$, a small quantity of the intermediate sized form (about $20 \%$ of totâl) was observed which was also protected against externally added protease (Fig.1, lanes 2 and 4). When lysate and mitochondria had been pretreated with apyrase, import was clearly diminished (Fig.1, lanes 1 and 3). Apyrase per se did reduce neither the protease resistance of endogenous mitochondrial proteins nor the amount of precursor proteins in the reticulocyte lysate (Pfanner and Neupert, 1986; Pfanner et al., 1987). We conclude that pretreatment with apyrase causes inhibition of import of cytochrome $b_{2}$ into mitochondria. 
To test whether the apyrase effect was due to depletion of NTPs, experiments were performed where ATP or GTP were included during import (Fig.2).

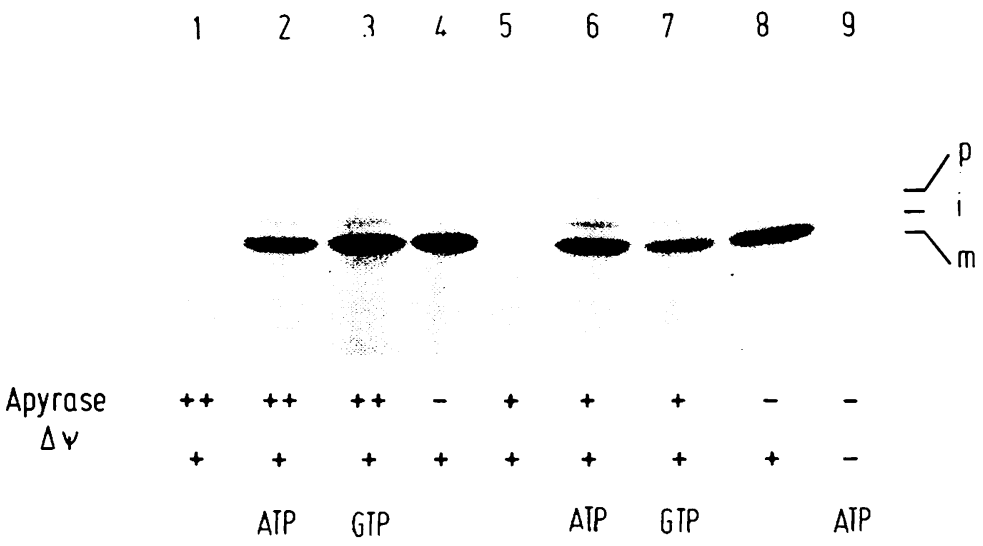

Fig. 2. Import of cytochrome $b_{2}$ from apyrase treated reticulocyte lysate is restored by addition of ATP or GTP.

Reticulocyte lysates and mitochondria were incubated with the following concentrations of apyrase: reactions $1-3,4 \mathrm{U} / \mathrm{ml}$; reactions $5-7,1 \mathrm{U} / \mathrm{ml}$; reaction 4 received $4 \mathrm{U}$ inactivated apyrase/ml and reactions 8 and $91 \mathrm{U} / \mathrm{ml}$. Import and protease treatment was performed as described in legend to Fig.1, except that in reactions 2,6 and $9,8 \mathrm{mM}$ ATP and in reactions 3 and 7 , $8 \mathrm{mM}$ GTP were added during import. In reaction $9,1 \mu \mathrm{M}$ valinomycin was added prior to ATP. A fluorograph of the dried gel is shown.

Abbreviations as in Fig.1. p, precursor of cytochrome $b_{2}$.

Under these conditions the import of cytochrome $b_{2}$ could be fully restored (Fig.2, lanes 2,3 and 6,7). This import, however, was completely abolished when valinomycin plus potassium ions were added to destroy the membrane potential across the inner membrane (Fig.2, lane 9). In this case, addition of ATP did not restore import.

The same result was obtained with import of cytochrome $c$ into mitochondria of N. crassa. Experimental conditions were essentially as described for import of cytochrome $b_{2}$, except that ascorbate/TMPD was used to establish a membrane potential and NADH was included, which is required for the second maturation step of cytochrome $c_{1}$ (Schleyer and Neupert, 1985, see accompanying article by Nicholson et al.). A fluorograph corresponding to the experimental design presented in Fig.2 was quantified by densitometry (Fig.3).

Again apyrase treatment drastically reduced import and processing (Fig.3, lanes 1,5) which could be restored by addition of ATP or GTP (Fig.3, lanes 2,3,6,7). Import was completely blocked after inhibition of the membrane potential with antimycin $A$ and oligomycin and could not be restored by including ATP in the reaction (Fig.3, lane 9). Consequently, the presence of NTPs and a membrane potential are two separate requirements. NTPs cannot substitute for the requirement of $\Delta \psi$. At present, 
however, it is unknown which form of high energy phosphate is actually needed since nucleoside phosphate kinases present in mitochondria can lead to formation of various nucleoside triphosphates.

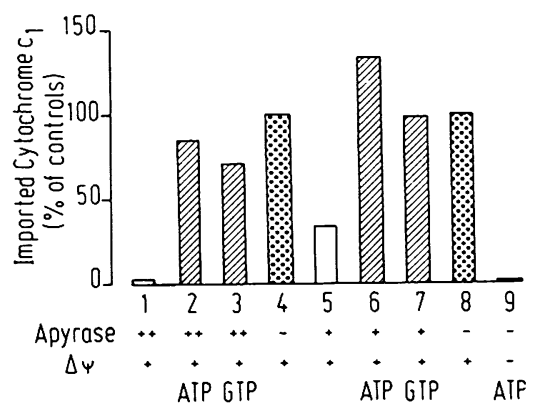

Fig. 3. Import of cytochrome $c_{1}$ is inhibited by apyrase treatment and restored by ATP or GTP.

The experimental design was essentially as described in the legend to Fig.2, except that mitochondria from N. crassa were used and import was performed in the presence of ascorbate/TMPD and $\mathrm{NADH}$ instead of succinate. Antimycin $\mathrm{A}$ was included in addition to oligomycin. Formation of mature cytochrome $c_{1}$ was quantified by densitometry of the fluorograph. The amount of mature $c_{1}$ formed in controls (inactivated apyrase) was set at $100 \%$.

Intermediate-sized cytochrome $b_{2}$ spanning outer and inner membranes at contact sites can be accumulated at low levels of NTPs

For precursors of $B$ subunit of $F_{1} F_{1}$-ATPase, cytochrome $c_{1}$ and the $\mathrm{Fe} / \mathrm{S}$-protein of complex III, it has been previously shown that import into mitochondria performed at lower temperatures results in the formation of so called "contact site intermediates" (Schleyer and Neupert, 1985; Hartl et al., 1986). Such an intermediate is characterized as follows: the N-terminal presequence of the precursor has been translocated across both membranes in a $\Delta \psi$ dependent manner and is cleaved of $f$ by the processing peptidase in the matrix. A large part of the polypeptide, however, is still outside the mitochondrion where it can be digested by externally added protease. It follows that these features can be only fulfilled at regions where outer and inner membranes are close enough together to be spanned by a single polypeptide chain.

Experiments with apyrase pretreatment indicated that after depletion of ATP the formation of intermediate-sized cytochrome $b_{2}$ was not reduced to the same extent as was processing to the mature form. In contrast to mature $b_{2}$, more than $85 \%$ of which were protease-resistent, this intermediate was largely sensitive to externally added protease. This effect could be clearly demonstrated when apyrase concentrations were titrated over a wider range ( 0 to $100 \mathrm{U}$ apyrase/ml of lysate or mitochondrial suspension). After import, one half of each reaction was treated with proteinase $\mathrm{K}$. Following electrophoresis and fluorography the 
amounts of intermediate-sized $b_{2}$ formed were quantified by densitometry (Fig. 4).

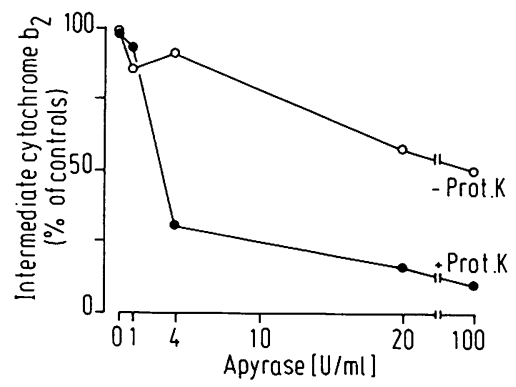

Fig 4. Intermediate sized cytochrome $b_{2}$ is accumulated in contact sites at low levels of NTPs.

Reticulocyte lysates and mitochondria were incubated with apyrase $(0-100 \mathrm{U} / \mathrm{ml})$. Controls received corresponding amounts of inactivated apyrase. Import and protease treatment were performed as described in the legend to Fig.1, except that only half of each sample received protease. Formation of intermediate cytochrome $b_{2}$ was quantified by densitometry of the fluorograph. ${ }^{2}$ The amount of intermediate $b_{2}$ formed in controls (inactivated apyrase) was set at ${ }^{2} 100 \%$.

At apyrase concentrations between 4 and $20 \mathrm{U} / \mathrm{ml}$, the formation of intermediate $\mathrm{b}_{2}$ was reduced by 10 to $40 \%$ compared to controls that had received inactivated apyrase. Most of this intermediate sized $b_{2}$, however, was digested by externally added proteinase $K$ thus fulfilling the criteria for a contact site intermediate described above. Only with very low concentrations of apyrase was intermediate-sized $b_{2}$ protected against externally added protease. Within a narrow range of 1 to $4 \mathrm{U}$ apyrase/ml, protease protection decreased from 95 to $30 \%$ indicating that only above a distinct level of NTPs import into protease protected position did take place. When the membrane potential was dissipated, no processing to intermediate $b_{2}$ was observed. We conclude that partial translocation of the precursor can occur at low levels of NTPs; this step depends on the potential across the inner membrane. For complete translocation, however, higher levels of NTPs are required.

\section{DISCUSSION}

The import of precursors of cytochromes $b_{2}$ and $c_{1}$ into mitochondria needs NTPs in addition to $\Delta \psi$. At Iow levels of NTPs, a translocational intermediate of cytochrome $b_{2}$ could be accumulated in contact sites.

Owing to the presence of nucleoside phosphate kinases it is unclear so far which form of high energy phosphate compound (eg. ATP or GTP) is the 
direct energy source. Non-hydrolyzable ATP-analogues could not restore import after depletion of NTPs with apyrase (Pfanner and Neupert, 1986) indicating that the mechanism of action of NTPs involves the hydrolysis of high energy phosphate bonds. The dependence of protein import into mitochondria on NTPs seems to be a general phenomenon. Similar effects have been recently observed with the precursors of $B$ subunit of $F_{F} F_{1}$ ATPase (Pfanner and Neupert, 1986) and the ADP/ATP-translocalor (Pfanner et al., 1987). Interestingly, the insertion of porin into the outer membrane (which is indeperident of $\Delta \Psi$ ) also seems to need NTPs (Kleene et al., in preparation).

What could be the role of N'TPs? Previous results had already suggested that NTPs modify the conformation of cytosolic mitochondrial precursor proteins (Pfanner et al., 1987). Eilers and Schatz (1986) have demonstrated that lack of tertiary structure is a prerequisite for protein import into mitochondria. Taking the resistance against digestion by protease as a measure for the degree of tertiary structure it could be shown that the presence of NTPs results in the unfolding of precursor molecules (Pfanner et al., 1987) thus rendering them competent for translocation across the mitochondrial membranes. In the present study, $\Delta \Psi$ dependent partial translocation of the precursor of cytochrome $b_{2}$ was possible at very low concentrations of NTPs resulting in an intêrmediate reaching into the matrix with its aminoterminus but having a large part of the molecule still outside the mitochondrion. Complete translocation into a protease protected position was then achieved by adding ATP or GTP and was independent of $\Delta \Psi$ (Hartl and Neupert, unpublished). These findings are consistent with the idea that the membrane potential is only necessary for the translocation of the aminoterminal part of the precursor across the inner membrane. It is assumed to exert an electrophoretic effect on the positive charges contained in the presequence (Pfanner and Neupert, 1985; Roise et al., 1986). Complete translocation of the precursor across both membranes is only possible when the polypeptide is kept in an unfolded state, the energy source for the unfolding reaction being NTPs. Specific binding of the precursor to receptors on the surface of mitochondria, insertion into and partial translocation across the mitochondrial membranes is possible at very low levels of NTPs; thus, it seems likely that the presequence folds independently of the mature part of the precursor and can be recognized by the mitochondrial import machinery. On the other hand it cannot be excluded that besides the unfolding of cytosolic precursors the role of NTPs includes functions such as the modification of mitochondrial membranes e.g. by phosphorylation of mitochondrial transport components.

The existence of "unfolding proteins" in the cytosol has been proposed (Rothman and Kornberg, 1986; Zimmermann and Meyer, 1986) that could bind to precursor proteins and whose action would involve the hydrolysis of high energy phosphate bonds. The role of NTPs in preventing (mis)folding of precursor proteins into an import incompetent conformation could explain the general importance of NTPs for the translocation of proteins across membranes in both procaryotic and eucaryotic systems (for review see Zimmermann and Meyer, 1986).

\section{ACKNOWLEDGEMENTS}

The authors wish to thank S. Meier for expert technical assistance and Dr. D. Nicholson for critically reading the manuscript. This work was supported by the Deutsche Forschungsgemeinschaft (SFB 184, B2). 


\section{REF'ERENCES}

Daum, G., Böhni, P.C., and Schatz, G. (1982a). J. Biol. Chem. 257, 13028-13033.

Daum, G., Gasser, S.M., and Schatz, G. (1982b). J. Biol. Chem. 257, $13075-13080$.

Eilers, M., and Schatz, G. (1986). Nature 322, 228-232.

Gasser, S.M., Daum, G., and Schatz, G. (1982). J. Biol. Chem. 257, 13034-13041.

Guiard, B. (1985). EMBO J. 4, 3265-3272.

Hallermayer, G., and Neupert, W. (1976). In "Genetics and Biogenesis of Chloroplasts and Mitochondria" (Bücher, T., Neupert, W., Sebald, W., and Werner, S., eds.) pp. 807-812. North Holland, Amsterdam.

Harmey, M.A. and Neupert W. (1985). In: The Enzymes of Biological Membranes (Martonosi A. ed.) Plenum Publ. Co. New York, Vol.4, p. 431-464.

Hartl, F.-U., Schmidt, B., Wachter, E., Weiss, H., and Neupert, W. (1986). Cell 47, 939-951.

Hartl, F.-U., Pfanner, N., and Neupert, W. (1987). Biochem. Soc. Trans. 15, 95-97.

Kolanski, D.M., Conboy, J.G., Fenon, W.A., and Rosenberg, L. (1982). J. Biol. Chem. 257, 8467-8471.

Krieg, P.A., and Melton, D.A. (1984). Nuc. Acid Res. 12, 7057-7070.

Laemmli, V.K. (1970). Nature (Lond.) 227, 680-685.

Li, Y., Leonard, W., and Weiss, H. (1981a). Eur. J. Biochem. 116, 199-205.

Nelson, N., and Schatz, G. (1979). Proc. Natl. Acad. Sci. USA 76, 4365-4369.

Ohashi, A., Gibson, J., Gregor, I., and Schatz, G. (1982). J. Biol. Chem. $257,13042-13047$.

Pfanner, N., and Neupert, W. (1985). EMBO J. 4, 2819-2825.

Pfanner, N., and Neupert, W. (1986). FEBS Lett. 209, 152-156.

Pfanner, N., and Neupert, W. (1987). In "Current Topics in Bioenergetics"

(C.P. Lee, ed.), Vol. 15, Academic Press, New York, in press.

Pfanner, N., Tropschug, M., and Neupert, W. (1987). Cell, in press.

Pratje, E., and Guiard, B. (1986) EMBO J. 5, 1313-1317.

Roise, D., Horvath, S.J., Tomich, J.M., Richards, J.H., and Schatz, G. (1986). EMBO J. 5, 1327-1334.

Rothman, J.E., and Kornberg, R.D. (1986). Nature 322, 209-210.

Schleyer, M., Schmidt, B., and Neupert, W. (1982). Eur. J. Biochem. $125,109-116$.

Schleyer, M. and Neupert, W. (1985). Cell 43, 339-350.

Stueber, D., Ibrahimi, I., Cutler, D., Dobberstein, B., and Bujard, H. (1984) EMBO J. 3, 3143-3148.

Teintze, M., Slaughter, M., Weiß, H., and Neupert, W. (1982). J. Biol. Chem. 257, 10364-10371.

Wikstrom, M., and Krab, K. (1982). Biochim. Biophys. Acta 549, 177-222.

Zimmermann, R., Hennig, B., and Neupert, W. (1981). Eur. J. Biochem. 116, $455-460$.

Zimmermann, R., and Meyer, D.I. (1986). Trends. Biochem. Sci. 11, 512-515 